\title{
PENGARUH FINANCIAL KNOWLEDGE, FINANCIAL ATTITUDE, DAN FINANCIAL RISK TOLERANCE TERHADAP FINANCIAL SATISFACTION
}

\author{
Bobby Natawiguna ${ }^{1}$, Ary Satria Pamungkas ${ }^{2}$ \\ ${ }^{1}$ Program Studi Manajemen, Fakultas Ekonomi dan Bisnis, Universitas Tarumanagara \\ Email: bnatawiguna10@gmail.com \\ ${ }^{2}$ Program Studi Manajemen, Fakultas Ekonomi dan Bisnis, Universitas Tarumanagara* \\ Email: aryp@fe.untar.ac.id \\ *Penulis Korespondensi
}

Masuk : 04-02-2021, revisi: 10-02-2021, diterima untuk diterbitkan :02-03-2021

\begin{abstract}
ABSTRAK
Tujuan dari penelitian ini adalah untuk menguji pengaruh Financial Knowledge, Financial Attitude, dan Financial Risk Tolerance terhadap Financial Satisfaction. Sampel pada penelitian ini adalah pengguna fintech yang sudah memiliki pendapatan di Jakarta. Sampel dipilih dengan metode convenience sampling yang berjumlah 174 responden dengan menyebarkan kuesioner online. Teknik analisis data yang digunakan adalah structural equation modeling yang dibantu dengan bantuan program SmartPLS.3.2.2. Hasil yang didapat pada penelitian ini menunjukkan bahwa terdapat pengaruh positif Financial Knowledge dan Financial Attitude terhadap Financial Satisfaction. Sedangkan Financial Risk Tolerance tidak memiliki pengaruh terhadap Financial Satisfaciton.
\end{abstract}

Kata Kunci: Financial Knowledge, Financial Attitude, Finacnial Risk Tolerance, Financial Satisfaction

\section{ABSTRACT}

The purpose of this research is to analyze the influence of Financial Knowledge, Financial Attitude, and Financial Risk Tolerance toward Financial Satisfaction. The subjects of this research are fintech users who already have income in Jakarta. Sample was selected using convenience sampling method amounted to 174 respondents through spreading questionnaire online. Data processing techniques using structural equation modeling what helped by SmartPLS.3.2.2 program. The result of this study reveals that Financial Knowledge and Financial Attitude have effects toward Financial Satisfaction, meanwhile Financial Risk Tolerance do not have effects toward Financial Satisfaction.

Keywords: Financial Knowledge, Financial Attitude, Finacnial Risk Tolerance, Financial Satisfaction

\section{PENDAHULUAN}

\section{Latar Belakang}

Berdasarkan laporan DailySocial 2018, layanan fintech sangatlah populer di Indonesia. Hal ini membuat masyarakat sangat bergantung terhadap fintech di dalam kehidupan sehari-harinya. Sebanyak 74,9\% masyarakat mengatakan bahwa layanan fintech ini sangatlah mudah untuk digunakan, 71,03\% masyarakat mengatakan layanan fitench sederhana, 62,67\% masyarakat menganggap bahwa layanan fintech memberikan efisiensi waktu dan 48,85\% masyarakat menganggap bahwa layanan fintech memiliki manajemen yang baik. Hal ini berdampak terhadap kepuasan para penggunanya.

Kepuasan merupakan salah satu bentuk kebahagiaan yang diperoleh dari hasil usaha yang telah dilakukan oleh individu. Kebahagian hidup merupakan pencapaian puncak seseorang dari sesuatu yang dikerjakan dengan keinginan individu. Salah satu bentuk kebahagiaan adalah melalui financial satisfaction. 
Menurut Easrterlin (2006), financial satisfaction berkontribusi besar terhadap kebahagiaan seseorang secara keseluruhan dibandingkan dengan kepuasan domain keluarga, kesehatan dan pekerjaan.

Terdapat beberapa faktor yang mempengaruhi financial satisfaction seseorang, diantaranya adalah financial knowledge, financial attitude, dan financial risk tolerance.

\section{Kajian teori}

\section{Financial Knowledge}

Menurut Kempson, Collard, \& Moore (2006) mendefinisikan financial knowledge sebagai kompetensi dan kesiapan seseorang dalam menghadapi masalah keuangan di dalam kehidupan sehari-hari.

\section{Financial Attitude}

Menurut Hogarth, Beverly, \& Hilgert (2003) "financial attitude is an individual characteristics related to managing the financial conditiion". Dari definisi financial attitude tersebut dapat diartikan sebagai karakteristik individu yang terkait dengan pengelolaan kondisi keuangan.

\section{Financial Risk Tolerance}

Menurut Grable \& Lytton (1999), "financial risk tolerance is fundamental issue underlying a number of financial decision and then helps to explain consumer behavior related to earnings, expenditures and savings choices regarding investment products, asset allocation plans and portfolio accumulation strategiest have been attribute to risk tolerance". Dari definisi financial risk tolerance tersebut dapat diartikan sebagai masalah dasar yang mendasari sejumlah keputusan keuangan dan kemudia membantu menjelaskan perilaku konsumen terkait pendapatan, pengeluaran, dan pilihan tabungan mengenai produk investasi, rencana alokasi aset dan strategi akumulasi portofolio yang dikaitkan dengan toleransi risiko.

\section{Financial Satisfaction}

Menurut Plagnol (2011), financial satisfaction dapat didefinisikan sebagai keadaan keuangan objektif seperti pendapatan dan kekayaan dan berkaitan dengan kebutuhan finansial yang dirasakan.

\section{Kaitan antar Variabel}

\section{Financial Knowledge terhadap Financial Satisfaction}

Ali et al. (2015) menyatakan bahwa financial knowledge yang lebih tinggi memberikan pengaruh positif terhadap perilaku keuangan seperti mengelola pendapatan, menabung, merencanakan dana pensiun dan investasi, serta menganggarkan dana bagi seseorang untuk meningkatkan kemampuan keuangannya yang berkontribusi pada financial satisfaction.

\section{Financial Attitude terhadap Financial Satisfaction}

Godwin (1994) menyatakan bahwa financial attitude memiliki dampak terhadap financial satisfaction. Semakin baik attitude seseorang terutama dalam hal keuangan, maka seseorang bisa menyimpan, menabung, investasi dan merencanakan keuangan dengan baik untuk masa depan.

\section{Financial Risk Tolerance terhadap Financial Satisfaction}

Jeong dan Hanna (2004) menyatakan bahwa financial risk tolerance memiliki pengaruh yang positif terhadap financial satisfaction. Semakin besar financial risk tolerance seseorang, maka semakin besar juga tingkat kepuasan finansial yang diterima. Dalam hal ini financial risk 
tolerace dapat dilihat secara positif dalam kaitannya dengan kesejahteraan keuangan. Dalam penelitian Joo dan Grable (2004) menyatakan bahwa perbedaan dalam menghadapi risk tolerance akan sangat mempengaruhi pola dan hasil investasi seseorang dimana dalam hal ini akan berpengaruh dan menyebabkan perubahan pada tingkat financial satisfaction seseorang.

\section{METODE PENELITIAN}

Populasi pada penelitian ini adalah seluruh pengguna fintech yang sudah mempunyai pendapatan di Jakarta. Teknik pemilihan sampel penelitian ini adalah dengan teknik convenience sampling dan didapatkan sebanyak 174 responden. Pengumpulan sampel dibantu dengan bantuan google form yang disebar secara online. Teknik analisis data yang digunakan adalah structural equation modeling yang dibantu dengan bantuan program SmartPLS 3.2.2. Suatu model penelitian harus memenuhi syarat valid dan reliabel, sehingga pada penelitian ini model akan diuji validitas dan reliabilitasnya. Setelah sebuah model penelitian memenuhi pesyaratan uji model pengukuran, tahap selanjutnya adalah melakukan analisis model struktural penelitian, kriteria yang harus dipenuhi dalam analisis model struktural meliputi nilai koefisien determinasi $\left(\mathrm{R}^{2}\right)$, predictive relevance $\left(\mathrm{Q}^{2}\right)$, effect size $\left(\mathrm{f}^{2}\right)$ dan path coefficients. Pada penelitian yang menggunakan PLSSEM, pengujian hipotesis dilakukan melalui nilai t-statistik dari sampel independen.

\section{HASIL DAN PEMBAHASAN}

\section{Hasil Uji Statistik}

Validitas dan Reliabilitas. Uji validitas pada penelitian ini dengan melihat nilai convergent validity dan discriminant validity. Convergent validity adalah sejauh mana indikator dalam konstruk yang sama berkorelasi secara positif. Convergent validity dapat dilakukan dengan menghitung nilai outer loading factor setiap indikator dan nilai Average Variance Extracted (AVE). Tabel 1. menunjukkan nilai AVE masing-masing variabel yang lebih besar dari 0,5 yang artinya memenuhi salah satu kriteria dari convergent validity.

Tabel 1. Hasil analisis Average Variance Extracted (AVE)

\begin{tabular}{|l|c|}
\hline \multicolumn{1}{|c|}{ Variabel } & Average Variance Extracted (AVE) \\
\hline Financial Knowledge & 0,729 \\
\hline Financial Attitude & 0,508 \\
\hline Financial Risk Tolerance & 0,509 \\
\hline Financial Satisfaction & 0,697 \\
\hline
\end{tabular}

Tabel 2. Hasil Nilai Loading Factor

\begin{tabular}{|l|r|r|r|r|}
\hline & Financial Attitude & Financial Knowledge & Financial Risk Tolerance & Financial Satisfaction \\
\hline FA1 & $\mathbf{0 , 7 1 4}$ & & & \\
\hline FA2 & $\mathbf{0 , 7 7 8}$ & & & \\
\hline FA3 & $\mathbf{0 , 7 2 2}$ & $\mathbf{0 , 7 6 5}$ & & \\
\hline FA4 & $\mathbf{0 , 6 2 7}$ & $\mathbf{0 , 9 3 9}$ & & \\
\hline FK1 & & $\mathbf{0 , 8 4 9}$ & $\mathbf{0 , 6 4 7}$ & \\
\hline FK2 & & & $\mathbf{0 , 7 8 7}$ & \\
\hline FK3 & & & $\mathbf{0 , 6 9 8}$ & \\
\hline FRT1 & & & $\mathbf{0 , 8 7 6}$ & \\
\hline FRT2 & & & $\mathbf{0 , 5 0 5}$ & \\
\hline FRT3 & & & & $\mathbf{0 , 8 5 3}$ \\
\hline FRT4 & & & & $\mathbf{0 , 8 7 5}$ \\
\hline FRT5 & & & & $\mathbf{0 , 7 9 8}$ \\
\hline FS1 & & & & \\
\hline FS2 & & & & \\
\hline FS3 & & & & \\
\hline FS4 & & & & \\
\hline
\end{tabular}




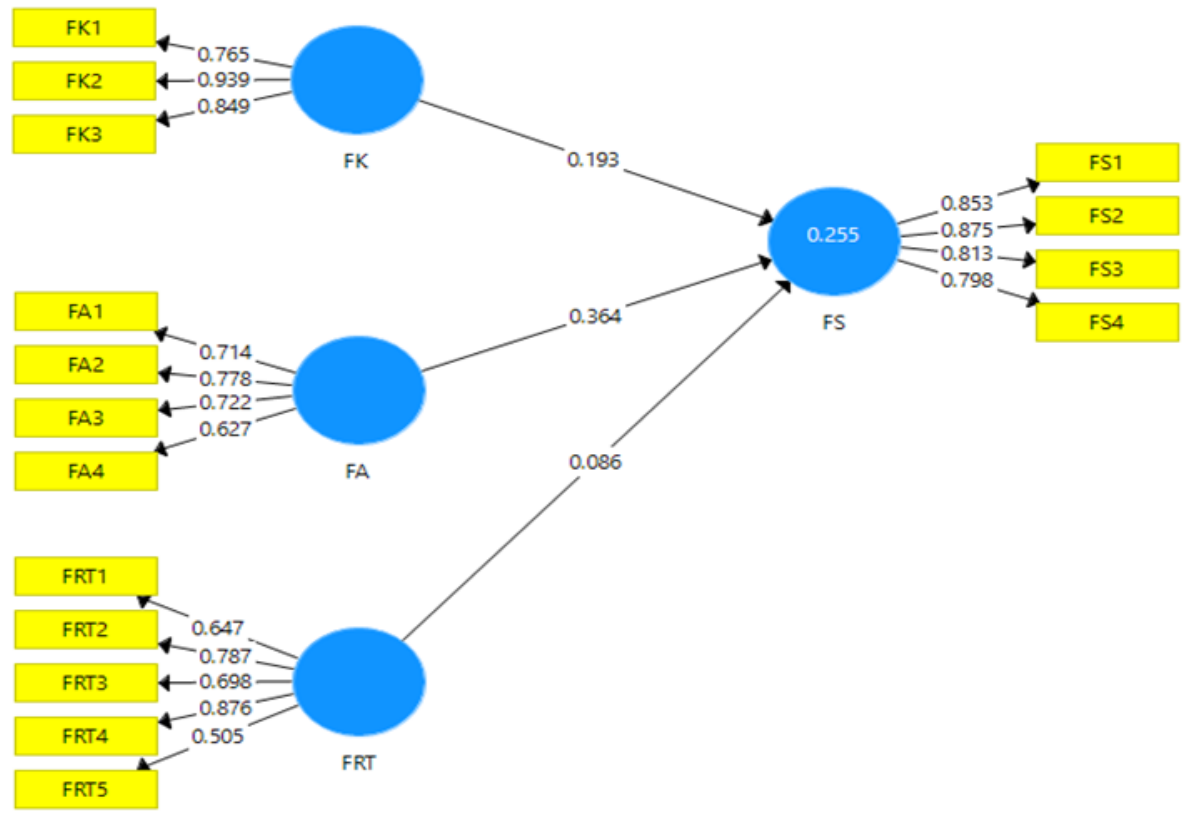

\section{Gambar 1. Hasil convergent validity}

Suatu instrumen dianggap valid dengan metode Fornell-Larcker, apabila nilai akar kuadrat AVE dari masing-masing konstruk lebih besar daripada korelasi dengan variabel laten lainnya. Demikian pula dengan pendekatan nilai cross loadings. Nilai loadings masingmasing indikator dari suatu konstruk harus lebih tinggi daripada nilai cross loadings indikator tersebut dalam konstruk lainnya. Berikut Tabel 3. yang menunjukkan hasil nilai cross loadings dari setiap indikator.

Tabel 3. Hasil nilai Cross Loading

\begin{tabular}{|l|c|c|c|c|}
\hline \multicolumn{1}{|c|}{ Variabel } & FA & FK & FRT & FS \\
\hline FA1 & 0,714 & 0,205 & 0,150 & 0,389 \\
\hline FA2 & 0,778 & 0,363 & 0,204 & 0,280 \\
\hline FA3 & 0,722 & 0,271 & 0,276 & 0,311 \\
\hline FA4 & 0,627 & 0,363 & 0,237 & 0,333 \\
\hline FK1 & 0,257 & 0,765 & $-0,018$ & 0,173 \\
\hline FK2 & 0,436 & 0,939 & 0,045 & 0,391 \\
\hline FK3 & 0,328 & 0,849 & 0,011 & 0,258 \\
\hline FRT1 & 0,151 & $-0,127$ & 0,647 & 0,061 \\
\hline FRT2 & 0,182 & 0,045 & 0,787 & 0,159 \\
\hline FRT3 & 0,157 & $-0,060$ & 0,698 & 0,086 \\
\hline FRT4 & 0,294 & 0,044 & 0,876 & 0,213 \\
\hline FRT5 & 0,243 & 0,069 & 0,505 & 0,108 \\
\hline FS1 & 0,357 & 0,296 & 0,133 & 0,853 \\
\hline FS2 & 0,404 & 0,281 & 0,145 & 0,875 \\
\hline FS3 & 0,387 & 0,202 & 0,366 & 0,813 \\
\hline FS4 & 0,417 & 0,372 & 0,033 & 0,798 \\
\hline
\end{tabular}

Tabel 3. menunjukkan nilai cross loading masing-masing indikator yang diteliti pada penelitian ini. Nilai cross loading masing-masing indikator menunjukan nilai yang lebih tinggi daripada nilai cross loadings indikator tersebut dalam konstruk lainnya. Maka kriteria dari discriminant validity dengan pendekatan nilai cross loading terpenuhi. Tabel 4. menunjukan hasil analisis nilai Fornell-Larcker dari setiap variabel yang akan disajikan di bawah ini. 
Tabel 4. Hasil Analisis Fornell-Larcker

\begin{tabular}{|l|r|r|r|r|}
\hline \multicolumn{1}{|c|}{ Variabel } & \multicolumn{1}{c|}{ FA } & \multicolumn{1}{c|}{ FK } & \multicolumn{1}{c|}{ FRT } & FS \\
\hline FA & 0,712 & & & \\
\hline FK & 0,416 & 0,854 & & \\
\hline FRT & 0,302 & 0,024 & 0,714 & \\
\hline FS & 0,470 & 0,347 & 0,201 & 0,835 \\
\hline
\end{tabular}

Tabel 4. menunjukkan nilai akar kuadrat AVE setiap variabel yang diteliti lebih besar dari korelasi antar variabel. Hasil tersebut menunjukan bahwa kriteria dari analisis fornell-larcker pada discriminant validity terpenuhi.

Suatu instrumen dinyatakan reliabel jika instrumen tersebut memiliki nilai Cronbach's alpha dan composite-reliability untuk tiap variabel lebih besar dari 0,6. Cronbach's alpha dan compositereliability pada variabel yang diteliti akan disajikan pada tabel 5. di bawah ini:

Tabel 5. Hasil analisis reliabilitas

\begin{tabular}{|l|c|c|}
\hline \multicolumn{1}{|c|}{ Variabel } & Cronbach's Alpha & Composite Reliability \\
\hline FA & 0,676 & 0,804 \\
\hline FK & 0,821 & 0,889 \\
\hline FRT & 0,761 & 0,834 \\
\hline FS & 0,855 & 0,902 \\
\hline
\end{tabular}

Tabel 5 di atas menunjukan nilai cronbach's alpha dan composite reliability masing- masing variabel yang diteliti memiliki nilai lebih besar dari 0,6. Maka variabel-variabel yang diteliti pada penelitian ini dapat dinyatakan reliabel.

Koefisien determinasi adalah ukuran dari akurasi prediksi sebuah model. Koefisien determinasi mewakili efek gabungan variabel eksogen pada variabel endogen, dengan kata lain koefisien determinasi bertujuan untuk melihat kontribusi variabel eksogen untuk memprediksi variabel endogen. Hasil koefisien determinasi akan ditampilkan pada tabel 6 berikut ini.

Tabel 6. Hasil Pengujian Koefisien Determinasi $\left(\mathrm{R}^{2}\right)$

\begin{tabular}{|l|l|}
\hline & R-Square \\
\hline Financial Satisfaction & 0,255 \\
\hline
\end{tabular}

Hasil pengujian koefisien determinasi $\left(\mathrm{R}^{2}\right)$ adalah sebesar 0,255 yang dapat diartikan bahwa 25,5\% dari varibel dependen yaitu financial satisfaction dapat dijelaskan oleh variabel independen financial knowledge, financial attitude, dan financial risk tolerance. Sisanya sebesar $74,5 \%$ dijelaskan oleh variabel-variabel lain di luar penelitian ini. Nilai koefisien determinasi yang diperoleh dari penelitian ini tergolong lemah.

Tabel 7. Hasil Boostrapping

\begin{tabular}{|l|c|c|c|}
\hline & Path Coefficients & $t$-statistics & $p$-values \\
\hline FA -> FS & 0,364 & 4,465 & $\mathbf{0 , 0 0 0}$ \\
\hline FK -> FS & 0,193 & 2,540 & $\mathbf{0 , 0 1 1}$ \\
\hline FRT -> FS & 0,086 & 1,051 & $\mathbf{0 , 2 9 4}$ \\
\hline
\end{tabular}

Berdasarkan Tabel 7 dapat disimpulkan persamaan dalam penelitian ini adalah $\mathrm{FS}=0,364 \mathrm{FA}+$ $0,193 \mathrm{FK}+0,086 \mathrm{FRT}$. Nilai path coefficients menunjukan bahwa nilai prediksi variabel financial attitude terhadap financial satisfaction memiliki arah yang positif sebesar 0,364 , nilai prediksi 
financial knowledge terhadap financial satisfaction memiliki arah yang positif sebesar 0,193; serta nilai prediksi financial risk tolerance terhadap financial satisfaction memiliki arah yang positif sebesar 0,086 .

\section{Pengujian Hipotesis}

Berdasarkan Tabel 7, dapat dilihat nilai p-values variabel financial knowledge terhadap financial satisfaction adalah 0,011 dimana nilai ini lebih kecil dari cut off value yaitu, 0,05, sedangkan nilai $t$-statistics nya adalah 2,540 dimana nilai ini lebih besar dari cut off value yaitu 1,96. Hal ini dapat disimpulkan bahwa terdapat pengaruh financial knowledge terhadap financial satisfaction.

Berdasarkan Tabel 7, dapat dilihat nilai p-values variabel financial attitude terhadap financial satisfaction adalah 0,000 dimana nilai ini lebih kecil dari cut off value yaitu, 0,05, sedangkan nilai $t$-statistics nya adalah 4,465 dimana nilai ini lebih besar dari cut off value yaitu 1,96. Hal ini dapat disimpulkan bahwa terdapat pengaruh financial attitude terhadap financial satisfaction.

Berdasarkan Tabel 7, dapat dilihat nilai p-values variabel financial risk tolerance terhadap financial satisfaction adalah 0,294 dimana nilai ini lebih besar dari cut off value yaitu, 0,05, sedangkan nilai $t$-statistics nya adalah 1,051 dimana nilai ini lebih kecil dari cut off value yaitu 1,96. Hal ini dapat disimpulkan bahwa tidak terdapat pengaruh financial risk tolerance terhadap financial satisfaction.

\section{Diskusi}

\section{Pengaruh Financial Knowledge terhadap Financial Satisfaction}

Hasil penelitian ini menunjukan terdapat pengaruh positif financial knowledge terhadap financial satisfaction. Hal ini dapat dilihat dari nilai p-values 0,011 dimana lebih kecil dari 0,05 dan nilai t-statistics 2,540 dimana lebih besar dari 1,96 sehingga dapat disimpulkan H1 diterima. Effect size dari financial knowledge yaitu sebesar 0,041 dimana variabel ini memiliki efek perubahan yang sedang. Penelitian ini selaras dengan penelitian sebelumnya yang dilakukan oleh Joo dan Grable (2004), Halim dan Astuti (2015), Coskuner (2016), dan Ali et al. (2019) dimana apabila seseorang memiliki financial knowledge maka tingkat financial satisfaction individu tersebut akan mengalami peningkatan.

Dalam penelitian ini, banyak responden yang menjawab setuju atas pernyataan-pernyataan dalam kuesioner untuk financial knowledge. Hal ini menunjukan bahwa responden memiliki pengetahuan dalam menangani masalah keuangan, pendapatan dan kebutuhan sehari-harinya.

\section{Pengaruh Financial Attitude terhadap Financial Satisfaction}

Hasil penelitian ini menunjukan terdapat pengaruh positif financial attitude terhadap financial satisfaction. Hal ini dapat dilihat dari nilai p-values 0,000 dimana lebih kecil dari 0,05 dan nilai $t$-statistics 4,465 dimana lebih besar dari 1,96 sehingga dapat disimpulkan $\mathrm{H} 2$ diterima. Penelitian ini selaras dengan penelitian sebelumnya yang dilakukan oleh Arifin (2018), Sawitri (2018), dan Caronge et al. (2019) dimana apabila seseorang memiliki financial attitude yang baik maka akan meningkatkan financial satisfaction individu tersebut.

Dalam penelitian ini, banyak responden yang menjawab setuju atas pernyataan dalam kuesioner untuk financial attitude. Hal ini menunjukan bahwa responden memiliki sikap yang baik dalam keuangan sehingga seseorang bisa menyimpan, menabung, investasi dan merencanakan keuangan dengan baik untuk masa depan. 


\section{Pengaruh Financial Risk Tolerance terhadap Financial Satisfaction}

Hasil penelitian ini menunjukan tidak terdapat pengaruh financial risk tolerance terhadap financial satisfaction. Hal ini dapat dilihat dari nilai p-values 0,294 dimana lebih besar dari 0,05 dan nilai $t$-statistics 1,051 dimana lebih kecil dari 1,96 sehingga dapat disimpulkan $\mathrm{H} 3$ ditolak. Effect size dari financial risk tolerance yaitu sebesar 0,009 dimana variabel ini memiliki efek perubahan yang lemah atau kecil.

Penelitian ini berbeda dengan hasil yang diteliti oleh Jeong dan Hanna (2004) dan Pratiwi (2019) dimana tingkat investasi dan risiko tidak dapat disamakan dengan tingkat kepuasan seseorang saat ini.

\section{KESIMPULAN DAN SARAN}

Berdasarkan hasil penelitian yang diperoleh, maka beberapa saran yang dapat disimpulkan adalah sebagai berikut:

1. Bagi peneliti selanjutnya, dapat menambahkan jumlah variabel independen dan yang mempengaruhi financial satisfaction seperti financial literacy, financial confidence, financial capability, financial planning, financial behavior, financial socialization dan sebagainya sehingga hasil yang didapatkan bisa menjadi lebih baik dan bermanfaat.

2. Bagi peneliti selanjutnya, disarankan untuk menambah jumlah sampel dan penyebaran kuesioner sekiranya dapat dilakukan kepada responden yang berada di wilayah selain Jakarta agar dapat memperoleh hasil temuan yang baru mengenai financial satisfaction atau kepuasan keuangan.

3. Bagi peneliti selanjutnya, untuk dapat memperluas ruang lingkup penelitian, sehingga tidak terbatas hanya terhadap financial satisfaction pada pengguna fintech.

4. Bagi penyedia layanan fintech untuk meningkatkan pelayanan dan sistem fintech sehingga dapat meningkatkan kepuasan keuangan para pengguna.

\section{REFERENSI}

Achjari, D. (2004). Partial Least Square: Another Method of Structural Equation Modeling Analysis. Jurnal Ekonomi dan Bisnis Indonesia, Vol. 19 No. 3, 238-248.

Ajzen, I. (1991). The Theory of Planned Behavior. Organizational Behavior and Human Decision Process, Vol. 50, 197-211.

Ali, e. a. (2019). Influence of Life Events on the Financial Satisfaction of Individuals. IBT Journal of Business Studies, Vol. 15 (1), 123-137.

Ali, e. a. (2020). Financial Satisfaction of International Students in Malaysia. Sarhad Journal of Management Sciences (SJMS), Vol. 6(Issue 1), 49-68.

Arifin, A. (2018). Influence Factors toward Financial Satisfaction with Financial Behavior as Intervening Variable on Jakarta Area Workforce. Europan Research Studies Journal, Vol. XXI(Issue 1), 90-103.

Armilia, N. \&. (2020). Faktor yang Mempengaruhi Kepuasan Keuangan Pengguna Financial Technology di Surabaya. Jurnal Ilmu Manajemen, vol. 8 No. 1, 39-50.

Baek, H. K. (2019). Financial Attitude, Knowledge, Investment Behavior and Satisfaction Among the Clients of Comprehensive Financial Planning Services. Financial Planning Research Journal, 11-28.

Caronge, e. a. (2019). Effects of Financial Attitudes, Financial Behavior and Financial Literacy to Financial Satisfaction in Women Workers (Case Study of Female Lecturer at Andi Djemma Palopo University). International Conference on Accounting Management and Economics. 
Coşkuner, S. (2016). Understanding Factors Affecting Financial Satisfaction: The Influence of Financial Behavior, Financial Knowledge and Demographics. Imperial Journal of Interdisciplinary Research (IJIR), Vol. 2(Issue 5), 377-385.

Dowling, N. A. (2009). Financial Management Practices and Money Attitudes as Determinants of Financial Problems and Dissastisfaction in Young Male Australian Workers. Association for Financial Counseling and Planning Education, Vol. 20(Issue 2), 5-13.

Garson, G. D. (2016). Partial Least Squares: Regression \& Structural Equation Models. Statistical Associates Publishing.

Grable, J. E. (2004). Environmental and Biopsychosocial Factors Associated with Financial Risk Tolerance. Association for Financial Counseling and Planning Education, Vol. 15 (1), 73 82.

Halim, Y. K. (2015). Financial Stressors, Financial Behavior, Risk Tolerance, Financial Solvency, Financial Knowledge, dan Kepuasan Finansial. FINESTA, Vol. 3 No. 1, 19-23.

Hira, T. K. (1998). Predictors of Financial Satisfaction: Differences Between Retirees and Nonretirees. Association of Financial Counseling and Planning Education, Vol. 9 (2), 75-84.

Jeong, W. \&. (2004). Risk Tolerance and Financial Satisfaction. International Journal of Human Ecology, Vol. 5 No. 1, 35-43.

Joo, S. \&. (2004). An Exploratory Framework of Determinants of Financial Satisfaction. Journal of Family and Economic Issues, Vol. 25 (1), 25-50.

Kirbis, I. S. (2017). Reliationship Between Financial Satisfaction and Financial Literacy: Exploring Gender Differences. Zagreb School of Economics and Management, 165-185.

Ozili, P. K. (2018). Impact of Digital Finance on Financial Inclusion and Stability. Borsa Istanbul Review, Vol. 18-4, 329-340.

Paluri, R. A. (2016). Financial Attitude Based Segmentation of Women in India: An Exploratory Study. International Journal of Bank Marketing, Vol. 34 No. 5, 670-689.

Parrotta, J. L. (1998). The Impact of Financial Attitudes and Knowledge on Financial Management and Satisfaction of Recently Married Individuals. Financial Counseling and Planning Education, Vol. 9 (2), 59-75.

Rai, K. D. (2019). Association of Financial Attitude, Financial Behavior and Financial Knowledge Towards Financial Literacy: A structural Equation Modeling Approach. FIIB Business Review, Vol. 8 (1), 51-60.

Robb, C. A. (2012). The Demand for Financial Professionals' advice: The Role of Financial Knowledge, Satisfaction, and Confidence. Financial Service Review, 291-305.

Rusdini, D. A. (2021). Faktor yang Mempengaruhi Financial Satisfaction Pada Masyarakat Kabupaten Pamekasan. Jurnal Ilmu Manajemen, Vol. 9 No. 1.

Saurabh, K. \&. (2018). Role of Financial Risk Attitude and Financial Behavior as Mediators in Financial Satisfaction Empirical Evidence From India. South Asian Journal of Business Studies, Vol. 7 No. 2, 207-224.

Saurabh, K. \&. (2019). Role of Financial Knowledge, Financial Socialization and Financial Risk Attitude in Financial Satisfactionof Indian Individuals. International Journal Indian Culture and Business Management, Vol. 18 No. 1, 104-122.

Sawitri, e. a. (2018). Behavior in Managing Revenue to Achieve Financial Satisfaction. Blibioteca Digital Repositorio Académico, 2477-9385.

Sherlyani, M. \&. (2020). Pengaruh Financial Behavior, Risk Tolerance, Financial Strain Terhadap Financial Satisfaction. Jurnal Manajerial dan Kewirausahaan, Vol. II No. 1, 272-281.

Sulaiman, E. K. (2012). An Empirical Analysis of Financial Risk Tolerance and Demographic Features of Individual Investor. Procedia Economics and Finance 2, 109-115. 
Wijaya, O. S. (2020). Pengaruh Financial Attitude, Financial Behavior, Financial Knowledge dan Risk Tolerance Terhadap Financial Satisfaction. Jurnal Manajerial dan Kewirausahaan, Vol. II No. 3, 631-642.

Wingdes, I. (2019). Pemanfaatan SEM PLS untuk Penelitian. Seminar Nasional Hasil Pengabdian Kepada Masyarakat (SINDIMAS), 43-48.

Yahaya, e. a. (2019). The Effect of Financial Knowledge, Financial Attitudes on Financial Behavior among University Students. International Journal of Academic Research in Business and Social Sciences, Vol. 9 No. 8, 23-32.

Yap, e. a. (2016). The Effect of Financial Literacy and Attitude on Financial Management Behavior and Satisfaction. International Journal of Administrative Science \& Organization, Vol. 23 No. 3, 140-146. 